\title{
Radial Fatigue Analysis of Automotive Wheel Rim(ISO 3006)
}

\author{
Priyam Deka \\ Department of Mechanical Engineering, \\ Gdansk University of Technology, \\ Poland \\ priyom.29@gmail.com
}

\author{
Faramarz Bagherzadeh \\ Department of Mechanical Engineering, \\ Gdansk University of Technology, \\ Poland \\ priyom.29@gmail.com
}

\author{
Sundeep Murugesan \\ Department of Mechanical Engineering, \\ Gdansk University of Technology, \\ Poland \\ priyom.29@gmail.com
}

\begin{abstract}
Due to many unexpected harsh environmental conditions of the road, automotive wheel is a vital part to ensure the vehicle safety and performance. ISO-3006 provides a comprehensive fatigue life experiment to validate proper wheels. This article is investigating a car wheel under the dynamic radial fatigue test of the ISO standard. This study aims to compare five different commercially available materials of the wheel concerning the ISO test conditions. As the wheel rim weight has a great impact on the performance of the vehicle, this comparison is considering the weight of the wheel made of various materials. The test is simulated via ANSYS software with a dens mesh to ensure the highest possible accuracy of results. Among selected materials, the CFRP is demonstrating the best fatigue strength to weight ratio in ISO radial fatigue test.
\end{abstract} 3006

Keywords-Radial Fatigue, CFRP, Wheel Analysis, ISO-

\section{INTRODUCTION}

The automotive wheel has a critical role in vehicle safety and performance; therefore it must meet a certain level of quality factors. Although the wheel strength can guarantee the minimum level of vehicle safety, wheel weight and inertia can significantly reduce the car performance. Decreasing the weight of the wheel via design modification is done for many years. The recent models had been altered many times. To have a wheel with higher performance and life, researchers are working on new alloys and composites.

The conventional and commercially available materials for wheel manufacturing are aluminum alloys, hot-rolled steel, magnesium alloys, and titanium alloys. Recently, composite materials became commercially available for wheel production, for example, carbon fiber reinforced plastic (CFRP) is an eye-catching material in the field[1].

As the maximum optimization is done on steel and aluminum wheels, obtaining a higher quality of the wheel is achievable through employing lighter materials. On the other hand, the manufacturing efficiency is a great concern for wheel producers. With growing the number of inventions in the composite field, new production methods are found to help the automotive industry for utilizing composite materials efficiently[2].

Often wheel manufacturing companies run a set of analysis of finite element method (FEM), before producing a prototype, and when all necessary tests are passed by prototypes, they plan for massive production. FEM is utilized to minimize the number of prototype failures. As computers are performing the FEM analysis automatically, there is a possibility to transfer data-driven from FEM structural analysis to an optimization program such as a neural network. Among a large amount of data, the best cases are selected concerning the desired factors and properties by the neural network[3].

Similarly, Pang[4] employed a multi-object optimization program by algorithms of genetic to optimize the wheel rim model. The FEM results of radial and bending fatigue tests were given to the optimization program. With this method, they obtained a $13 \%$ lighter wheel.

However, the wheel standardization depends on the origin of the manufacturer; several tests are common in all countries. Impact, rigidity, radial fatigue, and cornering (bending) fatigue are often performed by the international wheel producers.

The rigidity test is performed by Zheng [5], on a steel wheel. The wheel rim surface is dragged by its bolts to demonstrate the amount of displacement and deformation of the rim. During this research, the maximum deformation obtained by FEM results had less than $20 \%$ difference with experimental data.

The impact test is necessary when it comes to vehicle safety. In an accident, the automotive wheel may face a sudden momentum caused by an external object. This test is performed with different angles, depends on the standardization system. Recently, Gao[6] investigated a 90 impact test of a steel wheel. During this experiment, a sudden force is applied to the wheel in a radial direction. This test was studied via a FEM model, and the maximum deformation was $30 \%$ lower than the experimental results. In a similar manner, but with a tire on the wheel, Xiaofei [7]studied a 13 impact test for a car wheel. They believe the complexity of the tier should not be ignored in a FEM model, thus they designed the complex model of the tier. Finally, due to this suggestion, the FEM error was decreased to less than $5 \%$.

In most of the studies, the FEM model is considered isotropic, and production effects are ignored. Meng [8], demonstrated the influence of metal stamping on wheel strength. The stamping process causes thickness variation and strain hardening. By utilizing a data mapping method, they transferred the forming simulation data to the FEM model for fatigue analysis. The fatigue FEM simulation results indicate a considerable drop in simulation errors comparing to experimental values.

The wheel profile shape has a direct effect on the wheel life. Linghu [9], used Brown-Miller biaxial fatigue theory to optimize a steel wheel of a truck in Abaqus. The FEM 
analysis has been done for bending and radial fatigue analysis.

Considering long glass fiber reinforced (LGFT), Chai[10] suggests designing an anisotropic model of the composite via developing a donor mesh with fiber orientation tensors. The final result shows that the simplified isotropic model has a $36 \%$ error more than the anisotropic model.

Recently,Rapids [11] invented a novel method of the car wheel assembly and manufacturing which is made of carbon fiber reinforced plastic (CFRP). This technique has increased the wheel strength and stiffness up to $16 \%$. Another recent invention was established by Friske [12]. they suggested new form of spokes. These new spokes have H-beam and I-beam profile or wing-like extensions. With this method, they improved the integrity and interchangeability of the wheel.

Lots of research work was performed on wheel testing and analysis, but there is no comparison between various materials including CFRP. We implement a bending analysis with conventional materials and CFRP, to compare the material selection effects on the same model, therefore the readers of this article will find a general idea about the effect of material selection on the radial fatigue life of the wheel with considering the wheel weight effects.

\section{MATERIALS}

This article considers the most conventional materials of the wheel rim. The following materials are used for the cheap, middle class, sport, and luxurious cars. These materials are utilized by wheel manufacturer companies, tuning companies, and racing car producers. In this paper we have analyzed: CFRP, SAPH 440, Al 6061, Mg-AZ31B, Ti$6 \mathrm{Al}-4 \mathrm{~V}$.

Carbon fiber reinforced plastic (CFRP) has the lowest density while having considerably high fatigue strength[2].Concerning the CFRP T300, material properties, and fatigue life tests are obtained from $[13,14]$.

The hot-rolled steel (SAPH 440) formability, strength, and low price made it a favorable choice for middle-class and cheap cars. The low cost of manufacturing is a meaningful reason to select this steel $[5,15]$.

Sports cars and medium-class vehicles usually run on wheels made of aluminum alloys. Al 6061 is the grade which also used for aircraft components. The wheel manufacturing process begins with forging and ends with $\mathrm{CNC}$ machining of the artistic features on the wheel. Material properties are gained from [16,17]. Sports cars and medium-class vehicles usually run on wheels made of aluminum alloys. Al 6061 is the grade which also used for aircraft components. The wheel manufacturing process begins with forging and ends with CNC machining of the artistic features on the wheel. Material properties are gained from [16,17].

Weldability, corrosion resistance, ductility at room temperature, and significant strength to weight ratio have made the magnesium alloy $(\mathrm{Mg}-\mathrm{AZ} 31 \mathrm{~B})$ a good choice for components of aircrafts and racing cars. This alloy has a very high portion of zinc and aluminum. Mechanical and fatigue properties are obtained from $[17,18]$.

Ti-6Al-4V is the most popular alloy of titanium with a fascinating strength-to-weight ratio. Originally it was developed for aviation structural parts and then engineers used it in industrial oil refinery plants, wind turbine blades, and luxuries automobiles. Properties of this alloy are collected from $[17,19]$.

To explicate the fatigue characteristic of the mentioned materials, we combined them in one figure (Fig.1). This figure illustrates all the collected S-n curves.

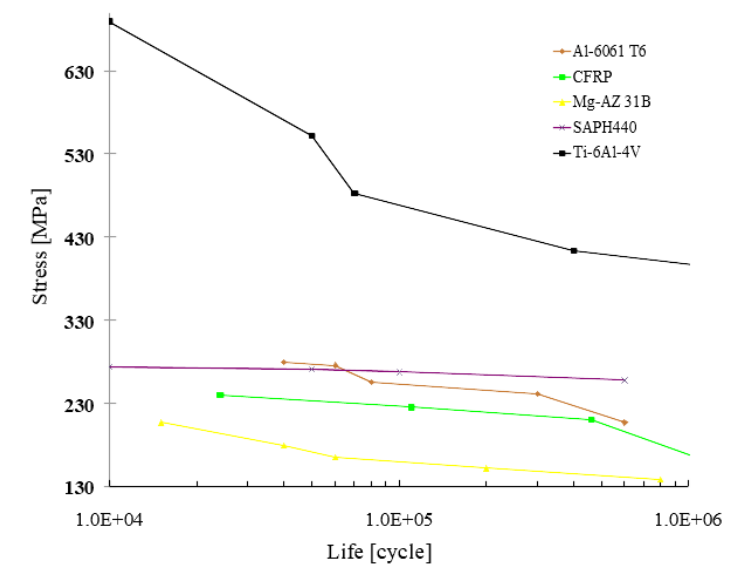

Fig. 1. S-n Curve of selected materials

\section{DYNAMIC RADIAL FATIGUE}

The automotive wheel is a vital component that guarantees the safety of the vehicle, thus it should be tested under specific terms and conditions. The international organization of standardization (ISO) defines a reliable procedure of testing to ensure the quality of the product. This well-known standard system gives a way of comparison between similar products all over the world. Consequently, customers can rely on the product which has the certificate of the ISO.

While driving a vehicle, various forces are applied to the car wheel rim. During driving a car, radial forces caused by the weight of the car are impacting the tire. The ISO (3006) is a standard test that simulates the radial load of the vehicle. In this test, the life of the wheel rim under a specific amount of loading will be tested.
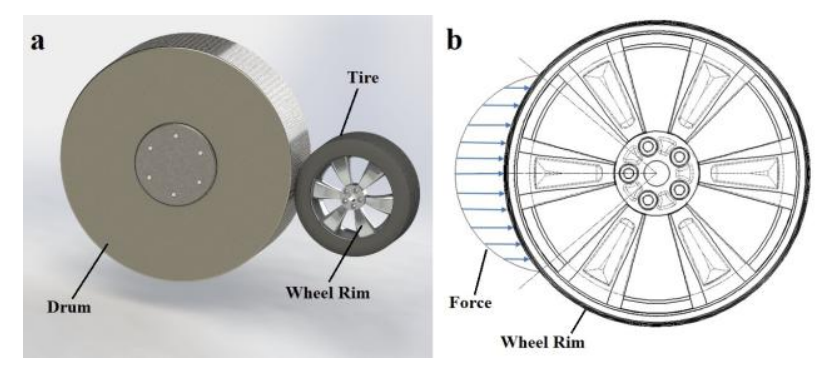

Fig. 2. ISO-3006 a) radial test b) uniformly distributed load applied to the wheel rim

The test includes a drum that is imparting a radial load on the wheel. The drum diameter should be a minimum $1.7 \mathrm{~m}$ and its section width must be larger than the tire. The test wheel axes and the drum axes are in a parallel position. The drum radial surface is in contact with the tire to apply the force to the wheel(Fig.2.a). The wheel rotation represents the number of cycles. The maximum expected force (defined by the manufacturer) is that is applied by the drum. The force is transferred to the wheel rim after pressing the tire. A 
uniformly distributed load is applied on the wheel rim surface (Fig.2.b). Finally, the test will terminate, if the wheel was unable to sustain more rotation cycles or if a crack appears on the wheel [20].

The Eq. 1 indicates the radial load $\left(F_{r}\right)$ for the test.

$$
F_{r}=F_{v} K
$$

where,

Fr-radial load for the test;

Fv-radial load specified by the wheel manufacture;

$\mathrm{K}$-accelerated test factor;

For performing a comparison study, we simulated the ISO test for a range of forces. This range generates minimum fatigue life from zero cycles (immediate failure) until cycles (safe life). The critical radial forces are calculated by (Eq.1) and are shown in (Table 1).

TABLE I. THE MAXIMUM RADIAL FORCE OBTAINED BY ISO-3006 FORMULA

\begin{tabular}{|c|c|c|c|c|c|}
\hline $\mathrm{K}$ & $\mathrm{F}_{\mathrm{v}}(\mathrm{N})$ & $\mathrm{F}_{\mathrm{r}}(\mathrm{N})$ & $\mathrm{K}$ & $\mathrm{F}_{\mathrm{v}}(\mathrm{N})$ & $\mathrm{F}_{\mathrm{r}}(\mathrm{N})$ \\
\hline 2.4 & 45000 & 108000 & 3.5 & 10104.3 & 35365.05 \\
\hline 2 & 45000 & 90000 & 3.4 & 10104.3 & 34354.62 \\
\hline 1.9 & 45000 & 85500 & 3.2 & 10104.3 & 32333.76 \\
\hline 1.8 & 45000 & 81000 & 2.8 & 10104.3 & 28292.04 \\
\hline 1.7 & 45000 & 76500 & 2.5 & 10104.3 & 25260.75 \\
\hline 1.6 & 45000 & 72000 & 2.25 & 10104.3 & 22734.675 \\
\hline 2 & 30000 & 60000 & 2.22 & 10104.3 & 22431.546 \\
\hline 2 & 25000 & 50000 & 1.9 & 10104.3 & 19198.17 \\
\hline 4.8 & 10104.3 & 48500.64 & 1.8 & 10104.3 & 18187.74 \\
\hline 4.4 & 10104.3 & 44458.92 & 1.7 & 10104.3 & 17177.31 \\
\hline 4.3 & 10104.3 & 43448.49 & 1.6 & 10104.3 & 16166.88 \\
\hline 4.2 & 10104.3 & 42438.06 & 1.4 & 10104.3 & 14146.02 \\
\hline 4.15 & 10104.3 & 41932.845 & 1.35 & 10104.3 & 13640.805 \\
\hline 4.1 & 10104.3 & 41427.63 & 1.33 & 10104.3 & 13438.719 \\
\hline 4 & 10104.3 & 40417.2 & 1.26 & 10104.3 & 12731.418 \\
\hline 3.9 & 10104.3 & 39406.77 & 1.1 & 10104.3 & 11114.73 \\
\hline 3.8 & 10104.3 & 38396.34 & 1 & 10104.3 & 10104.3 \\
\hline 3.6 & 10104.3 & 36375.48 & & & \\
\hline & & & & & \\
\hline
\end{tabular}

\section{Simulation}

Firstly, an automobile wheel is designed via SolidWorks software according to commercial tires and considering previous research works[21,22,23,24]. The wheel standard code is $215 / 45 R 20109 \mathrm{~V}$, and the inner dimensions are considered similar to previous research works. Next, the model was sent to ANSYS. A comprehensive material library for the mentioned materials was made. Then, a highdensity mesh with high quality was employed (Fig.3). The total amount of elements exceeds $375 \mathrm{k}$ to ensure the quality of the result.
According to the ISO-3006 test, the wheel was fixed on the drive axle in the hub area via bolts and nuts. Then the radial force was applied to form the drum. During the ANSYS simulation, the Goodman theory was used, and the load was fully reversed with 1.5 scale factors to apply sudden environmental harsh clashes.

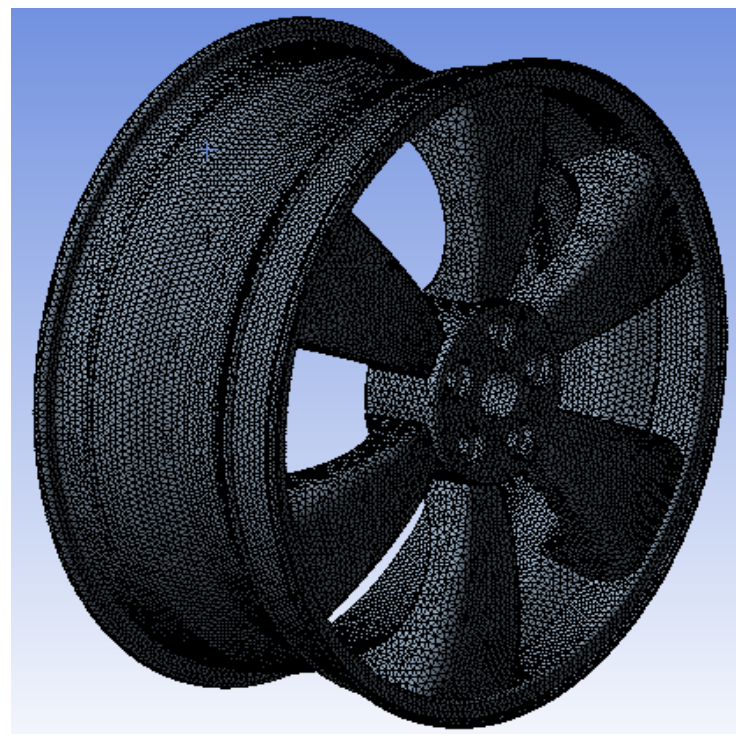

Fig. 3. High-density mesh

\section{RESULTS}

Considering the static loading, the maximum displacement occurs on the inner surface of the wheel rim and the maximum stress happens on the edges of designed spoke slots on the backside (Fig.4.).
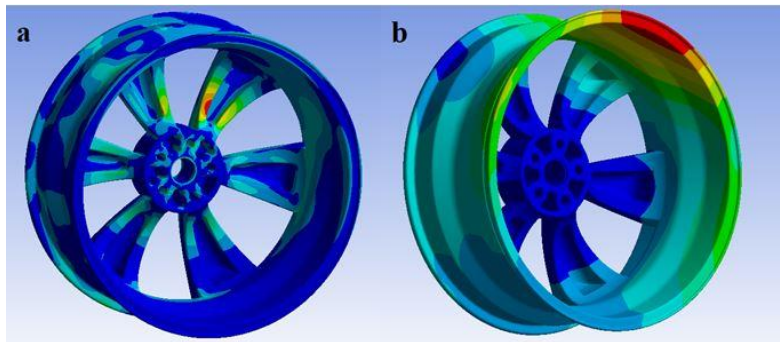

Fig. 4. Static results a) von-misses stress b) deformation

As we observe the maximum stress on the inner side of the spoke, we expect fatigue failure in that area too (Fig.5). We did not consider the manufacturing effects and we assumed the model to be isotropic, thus analysis error will appear considerably. As mentioned in the introduction, previous research works indicate a $30 \%$ to $40 \%$ error. We consider a 1.5 force scale to cover the analysis error.
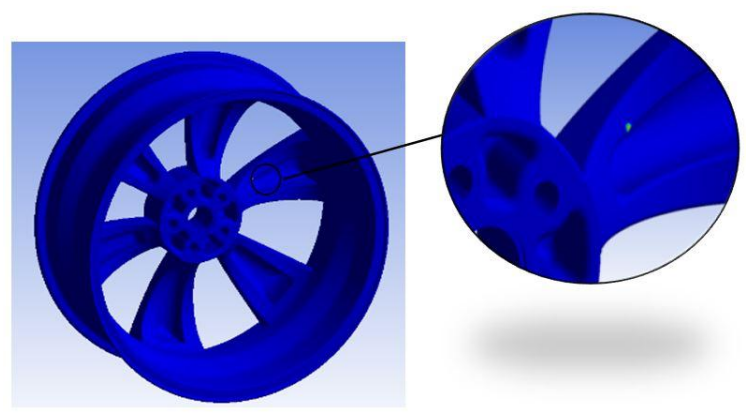

Fig. 5. Minimum fatigue life 
Concerning the five accounted materials, the results are described for a range of critical radial forces (Table1). A fatigue life representation is indicated in (Fig.6). For each radial force, the minimum fatigue life of the wheel is obtained via ANSYS simulation and analysis.

Considering Fig.6, Ti-6Al-4V and Mg-AZ31B has the maximum and minimum life respectively among the mentioned materials. CFRP, Al 6061, and SAPH 440 are very close to each other.

Although fatigue life is a vital factor, the density of the material is important too, because the weight of the wheel has a direct impact on vehicle performance. The following bar chart compares the radial force of materials at cycles besides the wheel weight for each one (Fig.7).

The steel alloy is the heaviest material among others, while fatigue stress is comparatively low. On the other hand, titanium alloy is more resilient, but it is heavier than CFRP, aluminum, and magnesium. The CFRP wheel is almost five times lighter than the steel alloy wheel, while the fatigue strength of CFRP is very close to steel alloy.

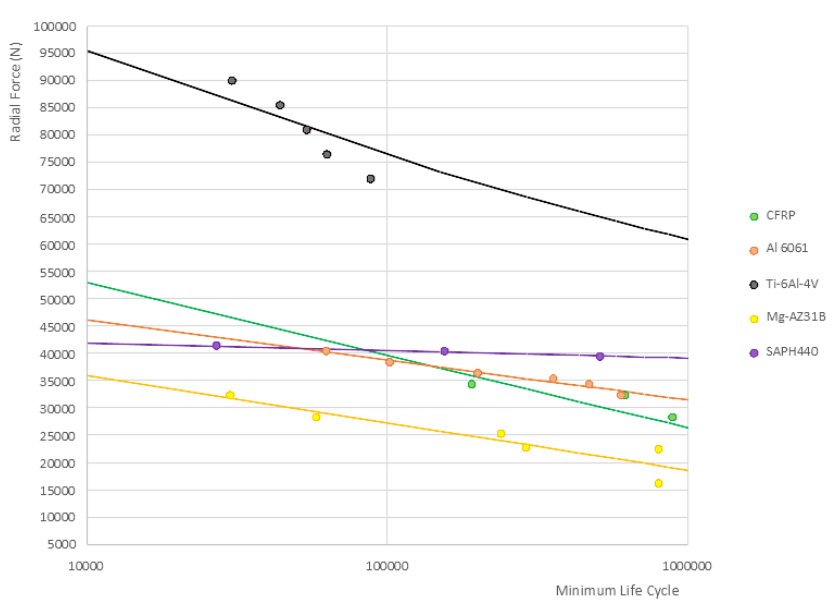

Fig. 6. Wheel fatigue life

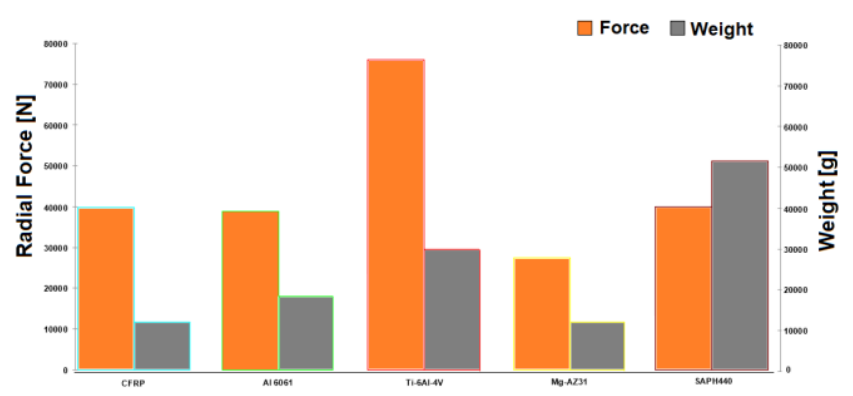

Fig. 7. Radial force at $10^{5}$ cycle and wheel weight

Although Fig.7 shows a comparison between fatigue strength and weight, all the available data is not included, thus another comparative figure (Fig.8) is described to elaborate the details. Concerning Fig.8, the Y-axis displays the radial force divided by wheel weight and the $\mathrm{X}$-axis is the fatigue life. The CFRP is more resilient respecting its lower weight. This comparison displays the cause for recent trends towards composite materials in the automotive industry.

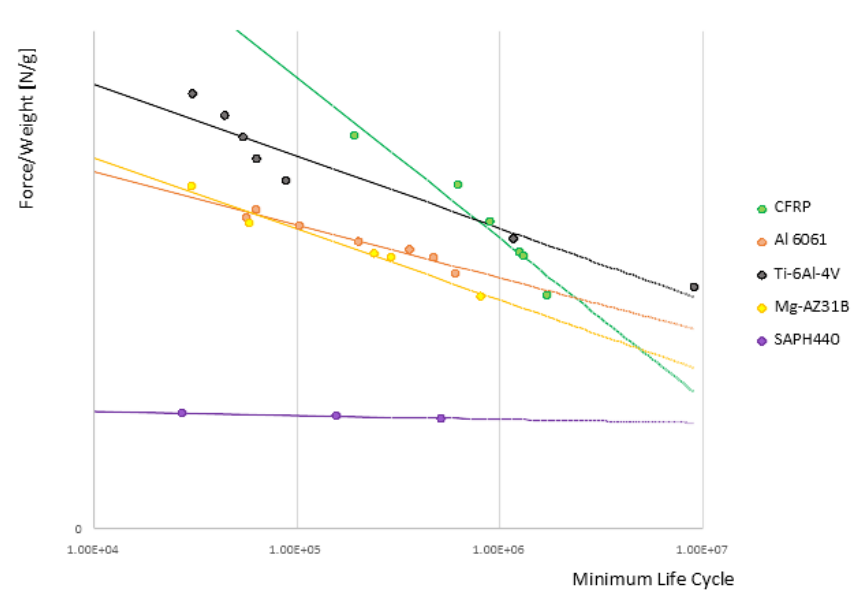

Fig. 8. Radial force to weight ratio and fatigue life

\section{CONCLUSION}

This article investigates the effect of dynamic radial force on the automotive wheel rim which is made of different materials. We focused on five common materials to perform a comparative study concerning the wheel fatigue test (ISO3006). The key points of the conclusion are as below:

1. The maximum stress happens on the inner side of the wheel on the edge of the wheel spoke slot, and the maximum displacement occurs around the inner edge of the rim.

2. Although the steel alloy can resist higher forces, comparing to CFRP and aluminum, the steel wheel is considerably heavier. The high density of steel alloy can decrease automobile performance significantly.

3. Regarding fatigue life, despite aluminum alloy and CFRP are very close to each other, CFRP isnearly $40 \%$ lighter.

4. The best mechanical properties are expressed by titanium alloy with an average long life span. A titanium wheel can endure extremely high amount of radial forces.

5. CFRP is almost the best option in our study if we consider radial forceto weight ratio. A composite wheel (CFRP T300) can promise the highest performance with reasonable fatigue strength.

\section{REFERENCES}

[1] N. Satyanarayana and C. Sambaiah, 'Fatigue Analysis of Aluminum Alloy Wheel Under Radial Load', Int. J. Mech. Ind. Eng., vol. 2, no. 1, pp. 1-6, 2012.

[2] S. Czypionka and F. Kienhöfer, 'Weight reduction of a carbon fibre composite wheel', Sci. Eng. Compos. Mater., vol. 26, no. 1, pp. 338346, 2019, doi: 10.1515/secm-2019-0018.

[3] Y. L. Hsu and M. S. Hsu, 'Weight reduction of aluminum disc wheels under fatigue constraints using a sequential neural network approximation method', Comput. Ind., vol. 46, no. 2, pp. 167-179, 2001, doi: 10.1016/s0166-3615(01)00125-7.

[4] W. Pang, W. Wang, W. Zhang, and X. Wang, 'Modeling and optimization for lightweight design of aluminum alloy wheel hub', Key Eng. Mater., vol. 723 KEM, pp. 322-328, 2017, doi: 10.4028/www.scientific.net/KEM.723.322.

[5] Z. G. Zheng, G. W. Cai, and Z. J. Li, 'Simulation of automotive wheel rigidity test', 2010 Int. Conf. Intell. Comput. Technol. Autom. ICICTA 2010, vol. 3, pp. 318-321, 2010, doi: 10.1109/ICICTA.2010.605. 
[6] Q. Gao, Y. Shan, X. Wan, Q. Feng, and X. Liu, '90-Degree Impact Bench Test and Simulation Analysis of Automotive Steel Wheel', Eng. Fail. Anal., vol. 105, no. June, pp. 143-155, 2019, doi: 10.1016/j.engfailanal.2019.06.097.

[7] X. Wan, X. Liu, Y. Shan, E. Jiang, and H. Yuan, 'Numerical and experimental investigation on the effect of tire on the $13^{\circ}$ impact test of automotive wheel', Adv. Eng. Softw., vol. 133, no. March, pp. 2027, 2019, doi: 10.1016/j.advengsoft.2019.04.005.

[8] J. Meng, P. Zhu, Z. Liu, and Q. Ji, 'Integration of multi-step stamping effects in the bending fatigue analysis of a steel wheel', Fatigue Fract. Eng. Mater. Struct., vol. 36, no. 8, pp. 795-808, 2013, doi: 10.1111/ffe. 12047 .

[9] K. Linghu, B. Xiao, D. Zhang, X. Li, F. Wang, and Z. Wang, 'Shape Optimization of Passenger Vehicle Wheel on Fatigue Failure', IOP Conf. Ser. Mater. Sci. Eng., vol. 381, no. 1, 2018, doi: 10.1088/1757899X/381/1/012025.

[10] W. Chai, X. Liu, Y. Shan, X. Wan, and E. Jiang, 'Research on simulation of the bending fatigue test of automotive wheel made of long glass fiber reinforced thermoplastic considering anisotropic property', Adv. Eng. Softw., vol. 116, no. November 2017, pp. 1-8, 2018, doi: 10.1016/j.advengsoft.2017.11.004.

[11] G. Rapids, G. Rapids, and R. U. S. A. Data, 'States Patent', vol. 2, 2020.

[12] Murphy et al., 'United States Patent: 5861366 United States Patent : 5861366', New York, vol. 2, no. 12, pp. 1-29, 2010.

[13] Torayca, 'T300 Data Sheet', No. CFA-001, pp. 6-7, 2002, [Online]. Available: www.toraycfa.com/pdfs/T300DataSheet.pdf.

[14] A. Amiri and M. N. Cavalli, 'Experimental investigation of fatigue behavior of carbon fiber composites using fully reversed four point bending test', Conf. Proc. Soc. Exp. Mech. Ser., vol. 7, no. January, pp. 131-137, 2013, doi: 10.1007/978-1-4614-4553-1_15.

[15] L. H. Zhao, H. C. Cai, S. Weng, and S. L. Zheng, 'Effect of pre-strain on the fatigue behavior of SAPH440 steel', Mater. Express, vol. 9, no. 9, pp. 1001-1008, 2019, doi: 10.1166/mex.2019.1586.
[16] R. Vijayakumar, C. Ramesh, R. Boobesh, R. Ram Surya, and P. Souder Rajesh, 'Investigation on automobile wheel rim aluminium 6061 and 6066 Alloys using ANSYS WORKBENCH', Mater. Today Proc., no. xxxx, 2020, doi: 10.1016/j.matpr.2020.03.798.

[17] A. V. Structures, 'Military Handbook Metallic Materials and Elements for', no. December, 1998.

[18] S. Suman, J. A. Abrol, and K. Ravi, 'Impact and modal analysis for different alloy wheel compositions', IOP Conf. Ser. Mater. Sci. Eng., vol. 263, no. 6, 2017, doi: 10.1088/1757-899X/263/6/062074.

[19] S. Thirumalvalavan and N. Senthilkumar, 'Experimental investigation and optimization of hvof spray parameters on wear resistance behaviour of TI-6AL-4V alloy', Comptes Rendus L'Academie Bulg. des Sci., vol. 72, no. 5, pp. 664-673, 2019, doi: 10.7546/CRABS.2019.05.15.

[20] F. O. R. Standardization and D. E. Normalisation, 'International Standard Iso', vol. 1987, 1987.

[21] JIANG Xin et al., 'Multi-objective Optimization Design of Magnesium Alloy Wheel Based on Topology Optimization', J. Mater. Sci. Eng. B, vol. 9, no. 1, pp. 13-24, 2019, doi: 10.17265/21616221/2019.1-2.003.

[22] S. S. Panda, J. Gurung, U. K. Chatterjee, and S. Sahoo, 'Modelingand-Fatigue-Analysis-of-Automotive-Wheel-Rim', Int. J. Eng. Sci. Res. Technol., vol. 5, no. 4, pp. 428-435, 2016, doi: 10.5281/zenodo.49728.

[23] L. Natrayan, P. Santhakumar, P. Dinesh, K. R. Mohan, U. Scholar, and R. Mohandass, 'Design and Comparative Analysis of Old \& New Model Car Wheel Rims with Various Materials', J. Res., vol. 02, no. 02, 2016.

[24] E. M. Adigio and E. O. Nangi, 'Computer Aided Design and Simulation of Radial Fatigue Test of Automobile Rim Using ANSYS', IOSR J. Mech. Civ. Eng., vol. 11, no. 1, pp. 68-73, 2014, doi: 10.9790/1684-11146873. 